\title{
Effects of SMS Texting on Academic Writing Skills of Undergraduate Students at a Public Sector University in Pakistan
}

\author{
Mohsin Ali Shah ${ }^{1 *} \quad$ Habib Ullah Pathan ${ }^{1} \quad$ Himat Shah $^{2} \quad$ Waqar Ali Shah ${ }^{1}$ \\ 1.Mehran University of Engineering and Technology Jamshoro Sindh Pakistan \\ 2.School of Computing, University of Eastern Finland Joensuu
}

\begin{abstract}
The growing concern about the use of texting endangering the standard forms in language prompted the present research to determine the presence or absence of SMS features in the academic writing of the participants. Triangulation was used for data collection i.e. questionnaires for learners and educators and samples of the learners' English written work were examined for SMS features. Simple average and ratio were used for descriptive analysis of the data. Contrary to the expectation, there were no significant evidences of these features in the sample. It seems being proficient in standard forms, these learners are context conscious and can switch to the appropriate register or style when writing formally. Thus the present study has demystified the popular belief about texting adversely affecting writing and thus destroying Standard English. Moreover, the evidences of one punctuation mark used in place of another indicate there can be other factors like carelessness or lack of knowledge of students and the lack of training, feedback or emphasis by educators or the system. So the matter of concern should be the general neglect of punctuation even out of the context of texting. It is found that the higher the exposure to the SMS, more the negative effect on the writing skills of the university students. The excessive use of this medium is leading students towards writing wrong spellings and using SMS language's short abbreviations that are not standard in examinations and daily academic work that is very harmful in academia.
\end{abstract}

Keywords: Orthography, Phonetic Transcriptions, SMS (texting), Writing skills

DOI: $10.7176 /$ JLLL/75-05

Publication date: January $31^{\text {st }} 2021$

\section{Introduction}

Writing in any language is basic source of communication, it is equally important, as is speaking. It helps human to exchange ideas and information in an easy way. Over the years, there have been variations in linguistic system which can be observed through diachronic study of any language. This phenomenon is discussed by linguistic under headings like 'language evolution' and 'language change' such changes in language is also evident in modern times due to globalization which has brought a large number of technologies in the global market. It is viewed by many scholars that with the advancement in technology including computers, I-pads, and mobile phones the text messaging has increasingly become very important for individuals. Writing a text message is important part of student's social as well as academic life. This exposure to text messaging is influencing student's academic writing in classroom negatively (Thurlow, 2006). The technology has shaped student's attitude that they do not have to put more efforts into their writing. Thus, they use very shortened form of a language in formal setting what they use in their SMS text, chat or emails. As a consequence of such exposure it has led to emerging trends in English language, and due to such technological developments the students feel difficult to distinguish between the formal and informal writing (Rosen et al, 2010). A number of scholars across the world have investigated the effects of technology on writing skills of English language. Crystal (2008) worked on the relation between language and internet notes. During his studies he observed, that a new variety of English is coming into play which he called as textese.

Today, this is a common scene that most of the young generation, especially students, while talking, walking, eating, reading, even in classroom, in front of teacher, continuously striking the keys of a device that seems to be a part of their hand, called cell phone, the most deliberate interactive media. That's all about messaging which is the recent development in the field of communication technology and the favorite of youth especially students around the globe due to its cheap tariff. The present study, however, is an attempt to explore the ways SMS texting affects the writing skills of undergraduate students at Mehran University of Engineering and Technology Jamshoro Sindh Pakistan.

\subsection{Statement of the problem}

The basic aim is to discover and study the impact of SMS usage on writing skills of students and to understand and identify whether or not if the e-language i.e. SMS/texting is affecting students' academic writing skills. In this study we address the problem of university undergraduate students writing skills influenced by the SMS writing. The gradual increase in use of SMS via internet and smart phones is negatively influencing writing skills of undergraduate students in Sindh Pakistan which is a threat to the standard variety of English language. Therefore, the strategies need to be formulated and implemented in the classroom so as to maintain the standards in formal 
writing.

\subsection{Aims and objectives}

The study aims to investigate the influence of SMS Texting on Writing Skills of Undergraduate Students at the Mehran University of Engineering and Technology Jamshoro Sindh. The following are the two broader objectives of the present study.

1. To investigate the morphological and syntactic distortion in writing skills of Undergraduate Students due to the influence of SMS texting.

2.To investigate whether or not the linguistic distortion affects the clarity of message.

\subsection{Research Questions}

RQ1: What kind of morphological and syntactical changes take place in writing skills of Undergraduate Students due to influence of SMS Texting?

RQ2: Whether or not the linguistic distortion affects the clarity of message?

\section{Literature Review}

SMS language is a term for the abbreviations and rebus-like slang most commonly used due to the essential pithiness of mobile phone text messaging etiquette. Context helps when interpreting SMS Language. The objective of SMS language is to use the least number of characters needed to convey an intelligible message as many telecommunication companies have an SMS character limit, allowing about 160 characters. Considering the relatively short history of mobile telephony in general and SMS text messaging in particular, it is rather amazing the level of interest it has generated among researchers and authors around the world. Not many books have been written on the subject yet. In 2007, Finnish author Hannu Luntiala published the first ever book written solely in text message language, about a business executive travelling throughout Europe and India. Crystal (2008), a renowned Linguistics Professor came out with his book entitled Txtng: The Gr8 Db8. This could be said to be the most comprehensive literary work so far on the SMS text messaging. Various researches on the impact of SMS texting have also been carried out and findings published in journals, newspapers, and on the internet. These articles, mostly online, address the positive and negative impacts of text messaging on various aspects of social life, including the academic work of students.

Dansieh, (2005) carried out a research to ascertain the veritable impact of SMS language on the writing skill of students of Wa Polytechnic in Ghana. The result reveals, struggle with grammar, lexis and structure. Therefore, text messaging which encourages abbreviating and non-conformity with grammatical rules could worsen students' written communication skills rather than improve them. The point of divergence is in the subject of study. While Dansieh, (2005) carried out his study among polytechnic students, this research investigates secondary school students.

However, several recent studies have looked specifically at the use of 'text messaging'. The book 'The Inside Text' (Harperet, Palen and Taylor, 2005) collects a number of studies of SMS use as well as designs issues in relation to digital text communication in a broader sense. Several studies of mobile phone use (including SMS) and only SMS use concentrate their observations on teenagers. Grinter and Eldridge (2001), for example, were among the first to explore the use of text messaging among teenagers, investigating why they have been so eager in their adoption of mobile phones and in particular text messaging. They describe how text messaging helps teenagers retain their privacy in a parent-controlled life and how they maintain social relations outside school. Alternatively, Taylor and Harper (2002) focus on the significance teenagers give to text messages themselves, comparing their communication to 'gift-giving' practices. Both studies emphasize the 'leisure and fun' aspects of the medium amongst their teenage user groups, although Ling (2004) later emphasizes how (virtually) all age groups in Norway use text messages for 'micro coordination' and organizational practicalities.

Studies carried out on French-speaking populations have confirmed the massive use of text messaging by adolescents. A study by Leo and Wolf (2004) and another by Samsung in 2006 in Belgium, found that $75 \%$ of the Belgian population owned a mobile phone. For $45 \%$ of Belgians, the exclusive function of a mobile phone was to make phone calls and send SMSes. Furthermore, $90 \%$ of those aged 15-35 used the SMS function. In France, according to the CREDOC study (Bigot \& Croutte, 2009), the proportion of mobile phone users rose from $24 \%$ in 1999 to $82 \%$ in 2009. In 2003, 57\% of mobile phone owners used the SMS function; in 2009, this proportion had reached $74 \%$. The younger the person, the more SMSes are used to communicate: $100 \%$ of young people between the ages of $12-17$ sent SMSes, $68 \%$ of those aged 4059 and only $21 \%$ of people over 70 years of age made use of this mobile phone function. The average weekly number of SMSes sent lies between 19 and 30 .

Crystal (2008) and Thurlow and Poff (2009) describe the same type of situation across different countries and different languages: the United States, the United Kingdom, Finland, Sweden, Norway, Germany, Italy, South Africa, Nigeria, New Zealand, Kuwait, Malaysia, Japan, Korea, China, Taiwan and Hong Kong. The massive data from the said countries postulates that the limited message lengths and tiny user interface of mobile phones make 
SMS users to commonly make extensive use of abbreviations, particularly the use of numbers for words, for example, "4" in place of the word "for", and the omission of vowels, as in the phrase "txt" "spk" are similar in that they reduce attention to spelling, punctuation, and grammar with words like "4u" ("for you") or "2gthr yrs $18 \mathrm{r}$ " ("together years later"). Also, Rosen (2009) is of the view that regular use of the service can impact negatively on the everyday language of "texters." In an unscientific poll conducted by Edutopia.org, out of 1028 respondents, $50 \%$ were of the view that texting was harming students' writing and grammar. $20 \%$ thought that text messaging could have some effect on students' writing; but did not consider it a major problem; while $27 \%$ felt it did not have any negative influence (Russell, 2010). One respondent was cited to have remarked “...my students' spelling is atrocious. Texting does not and has not helped".

In the same way, it would not make sense to expect the SMSes written by teenagers to resemble the written language such students use in an academic setting. The SMS messages will surely display different graphical, orthographical, and grammatical traits as well as an organization of discourse which deviates from the standard form (Crystal, 2001). According to them, SMSes are also able to fulfill different social functions.

Research concerning SMS messaging has revealed a great deal about the most obvious characteristic of SMSes: the use of orthographic forms which differ from those found in traditional writing. The specific spelling forms which have been invented are essentially neographic forms resulting from puzzle grams or the use of homophonic letters and numbers, phonological reductions, symbols, and acronyms (Crystal, 2008; Frehner, 2008). In this vein, many studies have specifically focused on the French language (Anis, 2007; Bouillaud, Chanquoy \& Gombert, 2007; Fairon \& Klein, 2010; Liénard, 2005, 2007; Panckhurst, 2009; Rivière \& Licoppe, 2005). SMS is just a phone language, thus, SMS is not meant for academic purposes but students consciously or unconsciously import this language in English formal writing examinations hence expression, content, organization and mechanical components are neglected to the core.

Véronis \& Guimier de Neef, (2006), like the first research carried out on oral language in the early 19th century by (McCarthy), highlighted the gender differences between girls and boys. In the area of computermediated writing, girls, as compared to boys, use SMS messaging more frequently, and send longer and more complex messages including more "emotional" content (Thurlow \& Poff, 2009). There are now sufficient available data to go beyond these most obvious orthographic traits of SMSes and focus in /on the other questions being examined in this area of research. One French language study (Rivière \& Licoppe, 2005) led the way by focusing on the addressees of SMS messages: SMSes are usually sent to close friends, no matter the age of the mobile phone user. The authors stressed the frequency of within-family SMS use between parents and their children, and the more limited use of SMSes in formal or professional settings. Emotional messages made up the majority of the exchanges. By working with a large corpus of SMSes collected in a natural situation (Fairon, Klein \& Paumier, 2006) by teenagers between the ages of 13-18, the role of the writers' characteristics (age, gender, and SMS experience) on the length of the SMSes they sent were examined. The study also focused on the functions of SMS messages (informative or relational). The objective was to show the extent to which the length and functions of SMSes varied according to the characteristics of the writers.

\section{Research Methodology}

The Methodology adopted for this study is Quantitative method which is defined as a systematic investigation of phenomena by gathering quantifiable data and performing statistical, mathematical, or computational techniques. Quantitative research collects information from existing and potential customers using sampling methods and sending out online surveys, online polls, questionnaires, etc., the results of which can be depicted in the form of numerical. (Creswell, 2002)

\section{Data collection and analysis}

Data used in this study is obtained through instruments such as, Essay writing and Questionnaire. A total of 100 participants were selected for which both male and female participants were contacted based on random sampling techniques. For the essay writing section, the participants were given to write an essay of $150-200$ words in a natural setting, following the one shot design. As for questionnaires, a total of two questionnaires were administered one for those students who were earlier called for paragraph writing to complete so that the results can be as true a representation of the population as possible For data analysis, the concept of Suppliance in Obligatory Contexts and SPSS software were used. This is a quantitative research. As statistical tools, percentage and average methods were used to analyze the data. Experiment was also conducted through a comprehensive assessment and evaluation by researchers for the paragraph written by students for this research. Then a quantitative data was derived from qualitative assessment. The surveys gathered from the respondents (students and educators) were considered for further analysis and findings of the said study.

\section{Finding and discussion}

The students were from two intact classes: bachelor of Electrical Engineering and Bachelor of Civil engineering, 
aged 19-25. 42 of them were males and 8 were females. The participating students had almost matching level of English proficiency, having studied English as a Second Language for 10-12 year before getting admission in these engineering programs with the exception of 8 students who had studied English for 6-10 years. In response to the question regarding how long they have been using mobile phone, 4 responded they had been using it for 8-10 years, 10 have been using it for 6-10 years, 28 students for 4-5 years and 8 students for 1-3 years. 31 of them started using mobile at 13-16 years of age, 10 at 11-12 years of age, 1 at 8-10 and 8 at 6-7 years. As for the frequency of texting for communication purpose (excluding forwarded messages), 21 text more than 50 SMS's, 13 text almost 50, and 16 students text between 5 to 20 messages per day. 9 of the 15 educators teaching English at the same level had 0-5 years' experience of teaching at this level, 5 had 6-10 years and 1 had 11-15 year of such experience. As for the frequency of assessing formal writing in a semester, 3 assess it 7 or more times, 11 assess it between 4 to 6 times and 1 assesses it 1-3 times. All 15 of them were of the opinion that their students' writing is affected by SMS language. As for the area of language most affected, 12 of the educators think spelling is the most affected area, 2 think that punctuation is the most affected area and 1 thinks grammar and tenses are mostly affected. 14 claim that they point out error caused by SMS language in their students' academic writing and 1 says he points them out sometimes. As for the mode of correcting or pointing out these errors, 8 say they point them out and diagnose the problem in writing on the script and/or in class orally for the benefit of all students in the group/class, 5 correct it in the student's script and 2 just underline such errors. Patterns of occurrence of punctuation marks present or missing in the written work of 50 students in obligatory contexts and in inappropriate contexts have been illustrated in Table 1. Moreover, the table shows the number of spelling typical of SMS language or abbreviated spelling and its ratio per student. Table 2 shows the ratio of patterns of occurrence of SMS features (namely omission of punctuation or spelling specific to SMS) to obligatory contexts in percentages. The use of these in inappropriate context has also been recorded but the data relevant to the present study i.e. features that can be considered typical of SMS language have been boldfaced for convenience. The findings of questionnaires meant for students reveal that a great majority of them i.e., $72 \%$ thinks their writing is affected by SMS language and $28 \%$ think it's not. While the same question answered by 15 educators teaching English at the same level in the same university reveal that $100 \%$ of them opine that their students' academic writing is affected by SMS language. Out of the 36 students who think it is affected, 30 students i.e. $83 \%$ think spelling is the most affected area of language, 5 students i.e. $14 \%$ think punctuation is mostly affected and 1 i.e. $3 \%$ think there are other effects mostly. Among the educators, $80 \%$ think spelling is the most affected area, $13 \%$ think punctuation is the most affected area and $7 \%$ of the educators think grammar and tenses are mostly affected. In this way, both the participating groups' opinions coincide and spelling can be considered the most affected area according to the opinion of the majority of educators and students. However, the data collected through the actual scripts of students' academic writing shows a totally different situation. The number of spelling affected by SMS writing is 0.04 per student, as shown in Table 1, which is negligible keeping in view the total number of words written by 50 students i.e., 7092 which means each student wrote 141.84 words on an average out of which 0.04 are affected by SMS language as shown in Table 1. Similarly, Table 2 shows out of every 100 words written, only 0.03 were found to be affected by SMS language. 2 words in a corpus of 7092 is not a matter of deep concern as Crystal (2008) points out, even very huge corpuses of SMS's display only a negligible proportion of abbreviated spelling. The two words they used were 'moto' instead of 'motto' and 'excessive' instead of 'excessive' which display omission of a double letter, not omission of vowels which is more specific to SMS Language. Omission of double letter can also be considered just an error in spelling. Omission of punctuation is another feature considered specific to SMS language or texting.

Out of the 880 full stops obligatory, 32 were missing which means on average, every student missed about 0.08 full stops as it is shown that the ratio of missed full stops to the number of obligatory contexts is $7.28 \%$. Moreover, it was also noticed that there were full stops at places where they were not required and they were recorded as the number of full stops misused/overused. They were 14 in number which means on an average, each student misused or overused 0.08 full stops.

As for the number of obligatory contexts for commas, they were 520 out of which 222 commas were found missing which means on an average, each student missed about 2.22 commas out of 4 obligatory commas. This means almost $45 \%$ commas were missed by students in their academic writing. The ratio of missed to obligatory contexts for commas is $55.88 \%$. But along with missing commas, there were many places where commas were not obligatory but students used them. These overused or misused commas were found to be 60 in number which means on average, each student used 0.12 extra commas. This draws attention to another assumption that this use, misuse, overuse or underuse of commas may be the result of lack of knowledge or training of obligatory contexts for commas. Moreover, as the students' majority pointed out their teachers have not been providing feedback about the use of SMS language in their academic writing, the educators, and not only the habit of texting, can also be held responsible for that to a great extent. If it were only the habit of texting to be blamed, students would not be using commas or full stops in inappropriate contexts or using them in place of full stops.

The number of obligatory contexts for apostrophe was 54 out of which only 2 were missing i.e. on an average, each student missed 0.04 apostrophes. Thus the ratio of the number of apostrophes missing to obligatory contexts 
is $7.40 \%$ as is obvious in Table 2 . At the same time, Table 2 shows apostrophes were misused or overused 26 times in the whole corpus. This again shows the lack of knowledge, training or awareness of obligatory contexts for apostrophes on the part of the learners. The number of question marks obligatory was 4 and no question mark was missing as shown in Table 1 and hence, the ratio of missing to obligatory contexts is $0 \%$ as shown in Table 2 . This means students are well aware of the context for the use of question mark and hence no impact of SMS language was found here. This is in keeping with Thurlow's finding that the use of full stop and question mark is generally consistent even in text messages. This is also perhaps due to the fact that these are the most basic punctuation marks and due to consistent reinforcement in education, learners and even texters use them automatically in both contexts. The need of the purpose of the statement to be understood as a question may also be a contributing factor.

The contexts obligatory for a quotation mark were 6 in the whole corpus out of which 5 were missing i.e. every student missed about 0.08 quotation marks and none of them misused or overused a quotation mark as is evident from Table 1. As far as apostrophe is concerned, texting done for communicating hardly requires quoting someone else's words so it cannot be counted as solely an effect caused by the use of frequent texting. The number of semi colons obligatory was 2 and it was not used which means on an average, each student missed 0.04 semi colons as shown in Table 1. The ratio of missed to obligatory semi colons is thus $100 \%$ as shown in Table 2 .As for its use in texting, there is hardly any need of the use of semi colons. Therefore, it cannot be considered solely an impact of frequent texting. Other factors might also be accounted for that. Semi colon is one of the least commonly used punctuation marks so it's not usually noticed carefully by people while reading anything and its instruction is hardly done in schools or colleges hence this neglect. The number of obligatory contexts for capital letters was 780 and the number of capital letters missing was 6 i.e. on an average each student missed about 0.12 capital letters as shown in Table 1 . The ratio of missing to obligatory context was $1.14 \%$ as shown in Table 2 . The number of capital letters misused or overused was 10 which shows a ratio of 0.2 per student as depicted in Table 1 . This tendency to misuse, underuse or overuse the full stop again depicts that factors other than frequent texting can also be responsible for this as it is not only a case of missing full stops which is considered a feature of texting. At 16 places in the whole corpus, a comma was used instead of a full stop which means on average, each student made this mistake 0.64 times and at 4 places, a full stop was used instead of a comma meaning each student did this error 0.08 times as shown in Table 1. This mis-punctuation is not a feature of SMS language so it cannot be attributed to the effects of texting by students. It can either be caused due to carelessness, lack of training of punctuation or lack of feedback by teachers as far as punctuation is concerned, or the students' lack of knowledge of the context for each punctuation mark or a combination of some of these factors.

\section{Conclusion}

As the result show that a two-third majority of the students feel difficulty in writing English and they often make spelling errors due to the SMS using habit that is too directly proportional to the excessive use of SMS. More than half of the respondents reported and worries about the problem in writing English in examination. These results discover that the manner people converse, as well as people writes, has been influenced by text messaging. Now it is evident that either texters are prone to ignore spellings, intentionally or reflectively. The accepted credence is that texting has been developed as a twenty-first century trend as a highly idiosyncratic vivid style, full of contractions and out of the ordinary uses of language, used by an immature generation that does not worry about standards. There is a broadly voiced apprehension that the practice is nurturing a decline in literacy. From the results obtained through the study, it is evident that mobile phone use among students is very high and using the device specifically for text messaging is also common. Empirical evidence from an environment where all respondents in the target group had English as their L2, proves that generalizing the positive impact of SMS text messaging on students' literacy as Crystal and some others claim could be misleading. Given the findings of this research, use of SMS language contributes to students' poor performance in essay writing. More so, an appreciable number of students equally struggle with grammar, lexis and structure.

Thus, the argument that SMS text messaging is a blessing because it helps improve students' written communication skills may hold water elsewhere; but not in English language. Evidence obtained from sampled marked scripts indicates that the harmful effects of text messaging on students' writing skills have become a major threat at the secondary school level. Be that as it may, it is important to eschew complacency and rather adopt conscious and pragmatic measures now so as to prevent the phenomenon from further worsening students' writing skills. All efforts must therefore be made to help students write good English whether on phone or on paper. The practice by some teachers of only marking content and not expression and mechanical accuracy, must cease immediately.

\section{Reference}

Boenisch, G. (2010). Cédric Fairon, Jean René Klein, Sébastien Paumier, Le langage sms. Étude d'un corpus informatisé à partir de l'enquête Faites don de vos. Questions de Communication, 17, 1-121. https://doi.org/10.4000/questionsdecommunication.272 
Dansieh, S. A. (2011). SMS Texting and Its Potential Impacts on Students' Written Communication Skills. International Journal of English Linguistics, 1(2), 222-229. https://doi.org/10.5539/ijel.v1n2p222

Creswell, J. W. (2011). Educational Research: Planning, Conducting, and Evaluating Quantitative and Qualitative Research (4th ed.). Pearson.

Crsytal, D. (1995) Language Play. London: Penguin Books.

Crsytal, D. (1997) English as a global Language.

Crystal, D. (2007). Txtng: The Gr8 Db8. Oxford: Oxford University Press.

Crystal, D. (2008). Txtng: The Gr8 Db8. Oxford: Oxford University Press.Cup levinson

Finnish, Author, Hannu Luntiala (2007)) Blurring the Boundaries: Cell Phones, Mobility, And the Line between Work and Personal Life. In Brown, B., Green, N. And Harper, R(eds.)wireless world. Springer.

Grinter, R., \& Eldridge, M. (2003). Wan2tlk? Everyday text messaging. Proceedings of the ACM Conference on human factors in computing systems.

Grinter, R.E. and M. A. Eldridge. (2003) Wan2tlk? Everyday text messaging. In Proceedings of CHI 2003. ACM Press.

Harper, R., Palen, L and Taylor A. (2005). The Inside Text. Springer. Harper, R., Palen, L and Taylor A.(eds.) (2003)The Inside Text. Springer. Herring, D. Stein \& T. Virtanen (Eds.), Handbook of the pragmatics of CMC. Berlin and New York: Mouton de Gruyter.

Hesse-Biber S. N. \& Leavy, P. (2011) The Practice of Qualitative Research (2nd ed.). Los Angeles: Sage Publications. http://dx.doi.org/10.1093/deafed/ enh04 http://faculty.washington.edu/thurlow/papers/Thurlow (2003)-DAOL.pdf

Jenson, S. (2005) Default Thinking: Why consumer products fail. In Harper, R., Palen, L and Taylor A. (eds.) The Inside Text. Springer. Johannesburg: ITU.

Knaś, A. (2010). Carmen Frehner, Email - SMS - MMS: The linguistic creativity of asynchronous discourse in the new media age. Bern: Peter Lang, 2008. Pp. 294. Pb \$78.95. Language in Society, 39(5), 713-714. https://doi.org/10.1017/s0047404510000813

Ling, R. (2004) The Mobile Connection. Germany, Elsevier. Ling, R. and B. Yttr, (1999) "Nobody sits at home and waits for the telephone to ring: Micro and hyper-coordination through the use of the mobile phone." Oslo, Telenor Research and Development, 1999.

Ling, R.\& peper (2005). The Socio-linguistics of SMS: An Analysis of SMS Use by a Random Sample of Norwegians. In R. Ling \& Pedersen (Eds.) Mobile Communications: Renegotiation of the Social Sphere. London: Springer Retrieved January 30, 2011.

Palen \& A. Taylor The Inside Text: Social, Cultural and Design Perspectives on SMS (pp. 33-50) Dordrecht, Springer. Pearson, J., Nelson, P. Titsworth, S., \& Harter, L. (2008) Human Communication (3rd ed).Boston: McGraw-Hill.124

Palen, L and Taylor A. (2001) The Inside Text. Springer. Rafi, M. S. (n.d.).(2011) SMS Text Analysis: Language, Gender and Current Practices. Retrieved February 27, 2011 from, http://www. Tesol france. Org.

Riviere, C. A. and C. Licoppe. (2002). From voice to text: continuity and change In the user of mobile phones in France and Japan. In Harper, R., Palen, L and Taylor A. (eds.) The Inside Text.

Rosen, S. (2009). The Impact of Text Messaging on Standard English. Retrieved February 15, 2011 from, The University of Bergen Website. https://bora.uib

Russell, L. (2010). The effects text messaging on English grammar.

Thurlow, C. \& Brown, A. (2003). Generation Txt? The sociolinguistics of young people's text messaging. Retrieved 28 July 2010.

Thurlow, C. \& Poff, M, (2011), Text Messaging, Handbook of the Pragmatics of CMC. Berlin \& New York: Mouton de Gruyters.

Thurlow, C. \& Poff, M. (2009). The language of text messaging. In S.C.

Véronis, J. \& Guimier de Neef, E. (2006). Le traitement des nouvelles forms de Communication écrite. In G. Sabah (Ed.), Compréhension automatique des Langues et interaction. Paris : Hermès Science. 